\title{
Clinical and histopathological factors associated with Ki-67 expression in breast cancer patients
}

\author{
GUL ALCO $^{1}$, ATILLA BOZDOGAN ${ }^{2}$, DERYA SELAMOGLU ${ }^{3}$, KEZBAN NUR PILANCI $^{4}$, SITKI TUZLALI ${ }^{5}$,

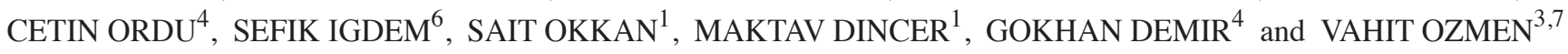 \\ ${ }^{1}$ Department of Radiation Oncology, Gayrettepe Florence Nightingale Hospital; \\ Departments of ${ }^{2}$ Biostatistics and ${ }^{3}$ Breast Surgery, Istanbul Florence Nightingale Hospital; \\ ${ }^{4}$ Department of Medical Oncology, Istanbul Bilim University; ${ }^{5}$ Department of Pathology, \\ Istanbul Florence Nightingale Hospital; ${ }^{6}$ Department of Radiation Oncology, Istanbul Bilim University, Gayrettepe, \\ Istanbul 34349; ${ }^{7}$ Department of General Surgery, Istanbul Medical Faculty, Istanbul University, Capa, Istanbul 34390, Turkey
}

Received February 10, 2014; Accepted October 24, 2014

DOI: $10.3892 / \mathrm{ol} .2015 .2852$

\begin{abstract}
The aim of the present study was to identify the optimal Ki-67 cut-off value in breast cancer (BC) patients, and investigate the association of $\mathrm{Ki}-67$ expression levels with other prognostic factors. Firstly, a retrospective search was performed to identify patients with stage I-III BC $(n=462)$. A range of Ki-67 index values were then assigned to five groups $(<10,10-14,15-19,20-24$ and $\geq 25 \%)$. The correlation between the Ki-67 index and other prognostic factors [age, tumor type, histological and nuclear grade, tumor size, multifocality, an in situ component, lymphovascular invasion (LVI), estrogen and progesterone receptor (ER/PR) expression, human epidermal growth factor receptor (HER-2) status, axillary involvement and tumor stage] were investigated in each group. The median Ki-67 value was revealed to be $20 \%$ (range, $1-95 \%$ ). A young age ( $\leq 40$ years old), tumor type, size and grade, LVI, ER/PR negativity and HER-2 positivity were revealed to be associated with the Ki-67 level. Furthermore, Ki-67 was demonstrated to be negatively correlated with ER/PR expression $(\mathrm{P}<0.001)$, but positively correlated with tumor size $(\mathrm{P}<0.001)$. The multivariate analysis revealed that a $\mathrm{Ki}-67$ value of $\geq 15 \%$ was associated with the largest number of poor prognostic factors $(\mathrm{P}=0.036)$. In addition, a Ki-67 value of $\geq 15 \%$ was identified to be statistically significant in association with certain luminal subtypes. The rate of disease-free survival was higher in patients with luminal A subtype BC $(\mathrm{P}=0.036)$. Following the correlation analysis for the Ki-67 index and the other prognostic factors, a Ki- 67 value of $\geq 15 \%$ was revealed to be the optimal cut-off level for BC patients.
\end{abstract}

Correspondence to: Dr Gül Alço, Department of Radiation Oncology, Gayrettepe Florence Nightingale Hospital, 8 Cemil Aslan Güder Sok, Gayrettepe, Istanbul 34349, Turkey

E-mail: gulalco@gmail.com

Key words: breast cancer, Ki-67, cut-off value, prognostic factors, molecular subtypes, age

\section{Introduction}

Breast cancer (BC) is a heterogeneous disease, with several different subtypes identified by immunohistochemical analyses and genetic array testing (1). Multigene tests have revealed that tumor proliferation has a significant effect upon predicting the risk of disease recurrence $(2,3)$. Although histopathological findings are used for disease management in patients with $\mathrm{BC}$, the assessment of tumor proliferation, in addition to conventional parameters, has become a key factor for treatment decisions (4).

In addition to the thymidine-labeling index, a range of techniques are available to assess the rates of tumor cell proliferation. These include the calculation of mitotic figures in stained tissue segments, flow cytometric analysis to identify the proportion of cells in the $S$ phase of the cell cycle and the expression analysis of the proliferating cell nuclear antigen or cyclins $\mathrm{E}$ and $\mathrm{D}(5-8)$.

The Ki-67 antigen is a labile, non-histone nuclear protein that was identified in the early 1980's. Ki-67 regulates the cell cycle, is associated with cellular proliferation and is the most widely used proliferation marker (9). Previous studies have demonstrated that $\mathrm{Ki}-67$ is expressed in all the active cell cycle phases, and not the resting $\mathrm{G}_{0}$ phase. Furthermore, Ki-67 has been used as a biomarker to assay the growth fraction of a given cell population $(10,11)$. A study that analyzed samples of normal breast tissue revealed that that $\mathrm{Ki}-67$ was expressed at low levels ( $<3 \%$ of cells) in estrogen receptor (ER)-negative cells, but was not detectable in ER-positive cells (12). Immunostaining techniques that use monoclonal $\mathrm{Ki}-67$ antibodies are able to assess the growth fraction of neoplastic cell populations. Although $\mathrm{Ki}-67$ is an accepted prognostic marker, the role of the protein in the management of $\mathrm{BC}$ is unclear. At present, a standard operating procedure, or generally accepted cut-off definition, are not defined for Ki-67 $(13,14)$.

Despite the observation that high Ki-67 levels are associated with worse prognoses and survival rates in patients with early $\mathrm{BC}(8,15)$, the marker has not yet been implemented for routine clinical use. Due to insufficient quality assurance and existing data, The College of American Pathologists (CAP) 
has not advised the routine use of $\mathrm{Ki}-67$ screening for the prognosis of patients with newly-identified BC (16). However, at the 2011 and 2013 St. Gallen Consensus Conferences, the use of Ki-67 screening was recommended for the analysis of cellular proliferation, and for identifying the differentiation status of luminal $\mathrm{A}$ and $\mathrm{B}$ tumors $(1,17)$. This was in agreement with a study published by Perou et al (18), which presented notable results with regard to intrinsic molecular BC subtypes.

Despite a decrease in the mortality rates and the number of $\mathrm{BC}$ cases in developed countries, the incidence of BC in developing countries, such as Turkey, is increasing (19). In addition, the prognoses and survival rates of patients are worse in developing countries due to a higher incidence of poor prognostic factors [including triple-negative $\mathrm{BC}$ (TNBC), tumor grade and proliferative indexes, and low hormone receptor (HR) positivity statuses], diagnoses at advanced stages and insufficient treatment regimens. A previous study revealed that in the past two decades, the incidence of $\mathrm{BC}$ has increased by more than two times in Turkey, with $20 \%$ of patients $<40$ years old, and half premenopausal (19). Although the results of this study may be due, in part, to the particular age structure of the population in Turkey, age-adjusted analysis revealed that there was a higher proportion of young females who had presented with $\mathrm{BC}$ in Turkey. Within this analysis, invasive ductal carcinoma (IDC) was identified as the most common BC histology (82\%), with the ER, progesterone receptor (PR) and human epidermal growth factor-2 (HER-2) receptor positive in 67, 52 and $23 \%$ of patients, respectively (19). Furthermore, $>50 \%$ of the patients had a histological grade (HG) III-type tumor, a high tumor proliferation rate and lymphovascular invasion (LVI).

The current study aimed to investigate the role of Ki-67 as a prognostic marker, to identify any correlations between Ki-67 expression and other clinical and histopathological parameters, and to determine the optimal cut-off value of $\mathrm{Ki}-67$ in a large cohort of females with BC.

\section{Materials and methods}

Patient selection, treatment and follow-up. Since January 2010, the Ki-67 index has been routinely used as a prognostic factor for patients with $\mathrm{BC}$ at the Breast Health Center, Florence Nightingale Hospital (Istanbul, Turkey). Between January 2010 and February 2013, 462 patients with invasive $\mathrm{BC}$ underwent surgery and their details were prospectively recorded. The electronic data from this cohort was then retrospectively analyzed. The follow-up period for this analysis continued until October 2013. The study was performed in accordance with the REMARK criteria (20). The patients included within the present study did not receive neoadjuvant treatment, and had a minimum one-year follow-up. Patients with a past malignancy, prior to developing $\mathrm{BC}$, and patients with syncrone/metacrone bilateral BC were not included. Written informed consent was obtained from all patients and this study was approved by the ethics commitee of Istanbul Bilim University (Istanbul, Turkey).

Current international guidelines were applied for treatment selections in a multidisciplinary tumor board (17). The Ki-67 value was taken into consideration for the treatment decisions, together with all other clinical and histopathological risk factors. The patients received doxorubicin $\left(60 \mathrm{mg} / \mathrm{m}^{2}\right)$ and cyclophosphamide $\left(600 \mathrm{mg} / \mathrm{m}^{2}\right)$ every 3 weeks for four cycles, node positive patients also received paclitaxel $(175 \mathrm{mg} /$ $\mathrm{m}^{2}$ every 3 weeks for 4 doses) or $\left(80 \mathrm{mg} / \mathrm{m}^{2}\right.$ weekly for 12 doses) or, docetaxel (100 mg/m $\mathrm{m}^{2}$ every 3 weeks for 4 doses or $35 \mathrm{mg} / \mathrm{m}^{2}$ weekly for 12 doses) and radiation therapy to the breast [median dose, 50 Gy (range, 46-50 Gy)], tumor bed [median dose, 14 Gy (range, 10-16 Gy)] and lymphatics [median dose, 46 Gy (range, 46-50 Gy)], when indicated. Hormone-naive patients were administered tamoxifen $(20 \mathrm{mg}$, once a day) or aromatase inhibitors (1 mg anastrozole, once a day; $2.5 \mathrm{mg}$ letrosole, once a day) for five years. In the absence of any medical contradictions, patients with HER-2 overexpression received trastuzumab for a one-year period. The patients were monitored every three months for the first two years, and every six months thereafter.

Immunohistochemistry. The automatized immunohistochemical staining was performed using the Ventana Benchmark LT (Ventana Medical Systems, Tucson, AZ, USA) according to the manufacturer's instructions. The monoclonal rabbit Ki-67 antibody (clone SP6; dilution 1:100; Biocare Medical, Concord, CA, USA), with an incubation time of $48 \mathrm{~min}$, was used as the primary antibody. The Ki-67 immunostaining was performed by an experienced breast pathologist. The immunohistochemical analysis of $\mathrm{Ki}-67$ was conducted following recommendations from the International Ki-67 in Breast Cancer Working Group (21). To calculate the Ki-67 proliferative index, the percentage of positively-stained cells, within the total number of malignant cells, were counted from the whole tissue sections. 'Positive staining' was regarded as the appearance of nuclear staining, of any intensity, within the tumor cells. The 'hot spots' at the edge of the invasive tumor were scored. The scoring was performed by counting a minimum of 500 invasive tumor cells. The normal ducts, lymphocytes and mitotic figures were used as internal positive controls, and sections from lymph nodes containing germinal centers were used as external positive controls.

The ER and PR expression analysis was performed using a rabbit monoclonal anti-human ER antibody (clone SP1; Neomarkers Inc., Fremont, CA, USA) at a 1/100 dilution, and a mouse monoclonal anti-human PR antibody (clone SP2; Neomarkers Inc.) at a 1/50 dilution. The ER and PR status was defined as the percentage of immunoreactive cells with an intranuclear staining of any intensity. The intranuclear staining of at least $1 \%$ of the cells was interpreted as a receptor-positive result (22). The HER-2 expression analysis was performed using a mouse monoclonal antibody (clone SP3; Neomarkers Inc.) at a 1/100 dilution. The interpretation analysis was performed according to the American Society of Clinical Oncology/CAP guidelines (23).

Definition of molecular subtypes. The molecular subtypes were defined as luminal A or B (B1/B2), HER-2 enriched and triple-negative (Table I).

Study design. In order to identify the optimal cut-off value of $\mathrm{Ki}-67$, the distribution of $\mathrm{Ki}-67$ immunostaining levels were divided into five groups $(<10,10-14,15-19,20-24$ and $\geq 25 \%)$. The correlation between Ki-67 and other conventional prognostic factors [age, tumor type, multifocality/multicentricity, 
Table I. Median Ki-67 levels according to molecular classification and histological type.

\begin{tabular}{|c|c|c|c|c|}
\hline Tumor characteristics & $\mathrm{n}$ & $\%$ & Median Ki-67, \% & Median tumor size, $\mathrm{mm}$ \\
\hline \multicolumn{5}{|l|}{ Molecular subtype } \\
\hline Luminal A/B1 (ER/PR+HER') & 313 & 67.7 & 10 & 20.0 \\
\hline Luminal B2 (ER/PR $\left.{ }^{+} \mathrm{HER}^{+}\right)$ & 66 & 14.3 & 30 & 20.0 \\
\hline Triple negative (ER-PR-HER2-) & 50 & 10.8 & 75 & 24.5 \\
\hline HER-2-enriched (ER-PR-HER2+') & 33 & 7.1 & 40 & 28.0 \\
\hline Total & 462 & 100.0 & 20 & 20.0 \\
\hline \multicolumn{5}{|l|}{ Histological type } \\
\hline Invasive ductal cancer & 368 & 79.7 & 20 & \\
\hline Other & 94 & 20.3 & 10 & \\
\hline
\end{tabular}

HER, human epidermal growth factor receptor; ER, estrogen receptor; PR, progesterone receptor.

HG, according to the Nottingham grading system (24), nuclear grade (NG), according to Fisher's modification of Black's nuclear grading system (25), LVI, in situ component, tumor size, pathological tumoral (pT) and pathological nodal (pN) stages, and ER, PR and HER-2 status] was investigated for each group. Subsequent to quantitative comparison, four different Ki-67 cut-off values ( $\geq 10, \geq 15, \geq 20$ and $\geq 25 \%$ ) were defined. In addition, multivariate analysis was performed to identify any correlations between the Ki-67 cut-off values, the largest number of poor prognostic factors and the disease-free survival (DFS) rate.

Statistical analysis. Statistical analyses were performed using SPSS 17.0 for Windows software (SPSS Inc., Chicago, IL, USA). The assessment of the association between Ki-67 expression and other prognostic factors was performed using $\chi^{2}$ tests (Pearson $\chi^{2}$, continuity correction and Fisher's exact tests). In order to identify the independent prognostic factors associated with Ki-67 expression, a multivariate analysis using a logistic regression model was performed. The DFS rates were calculated using the Kaplan-Meier method. The differences in the DFS rates were evaluated using the logrank test. DFS was defined as the time from diagnosis to the first locoregional tumor recurrence. The overall survival (OS) time was calculated as the length of time from BC diagnosis, until mortality from any cause. All P-values were two-sided, and $\mathrm{P}<0.05$ was used to indicate a statistically significant difference.

\section{Results}

Patient characteristics. The patient characteristics are summarized in Table II. The median age was 49 years (range, 23-87 years), with $24.5 \%$ of the patients younger than 40 years old. The median Ki-67 level was $20 \%$ (range, 1-95\%), and the majority of patients $(80 \%)$ presented with IDC. Tumor multifocality/multicentricity, LVI and an in situ component were present in 17, 45 and $72 \%$ of cases, respectively. The ER, PR and HER-2 positivity rates were 81,67 and $21 \%$, respectively. In total, $53 \%$ of the patients presented with modified Scarff-Bloom-Richardson grade III tumors, and $61 \%$ exhibited $\mathrm{Ki}-67$ levels of $\geq 15 \%$. The pathological stage III rate was $21 \%$,

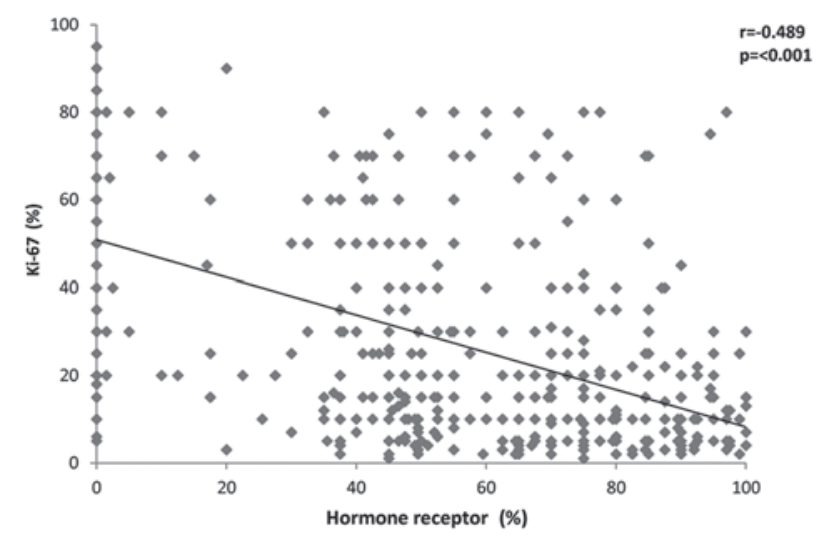

Figure 1. Regression analysis revealing the association between the hormone receptor positivity ratios and $\mathrm{Ki}-67$ expression $(n=462)$.

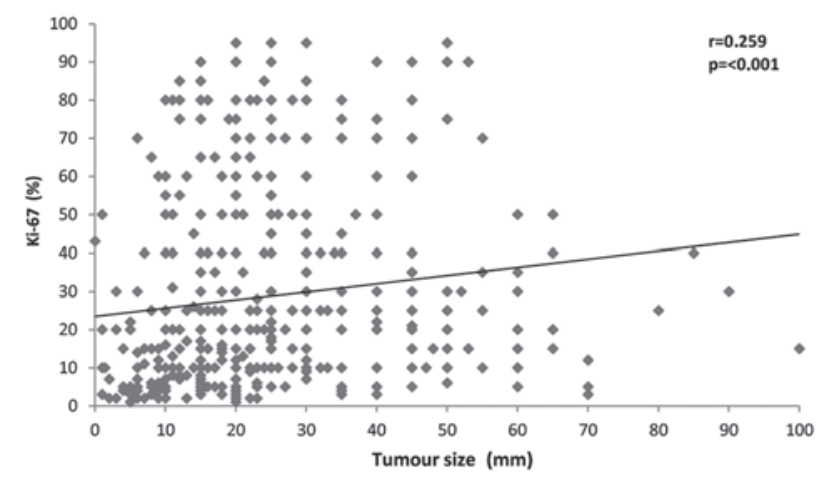

Figure 2. Regression analysis revealing the association between Ki67 expression and tumor size $(n=462)$.

and the median tumor size was $20 \mathrm{~mm}$. The median Ki-67 values and tumor sizes differed according to the distinct molecular subtypes of BC (Table I). The values were smallest in the luminal A group, and largest in the HER-2-enriched group.

Qualitative and quantitative comparisons. Subsequent to quantitative comparisons, a young age ( $\leq 40$ years old; $\mathrm{P}<0.001)$, histological type (IDC; $\mathrm{P}=0.001)$, pT stage (pTII-III; $\mathrm{P}<0.001$ ), a high grade (HG/NG III; $\mathrm{P}<0.001)$, LVI $(\mathrm{P}=0.001), \mathrm{ER} / \mathrm{PR}$ 
Table II. Patients characteristics $(n=462)$.

\begin{tabular}{|c|c|c|c|c|}
\hline Patient characteristics & $\mathrm{n}$ & $\%$ & Median & Min-max \\
\hline Age, years & 462 & - & 49 & $23-87$ \\
\hline$\leq 40$ & 113 & 24.5 & & \\
\hline$>40$ & 349 & 75.5 & & \\
\hline \multicolumn{5}{|l|}{ Tumor type } \\
\hline IDC & 368 & 79.7 & & \\
\hline ILC & 20 & 4.3 & & \\
\hline Other & 74 & 16.0 & & \\
\hline \multicolumn{5}{|l|}{ Focality } \\
\hline Unifocal & 384 & 83.1 & & \\
\hline Multifocal/multicentric & 78 & 16.9 & & \\
\hline \multicolumn{5}{|l|}{ Histological grade } \\
\hline I-II & 216 & 46.8 & & \\
\hline III & 246 & 53.2 & & \\
\hline \multicolumn{5}{|l|}{ Nuclear grade } \\
\hline I-II & 173 & 37.4 & & \\
\hline III & 289 & 62.6 & & \\
\hline \multicolumn{5}{|l|}{ Lymphovascular invasion } \\
\hline Present & 209 & 45.2 & & \\
\hline Absent & 253 & 54.8 & & \\
\hline \multicolumn{5}{|l|}{ DCIS } \\
\hline Present & 332 & 71.9 & & \\
\hline Absent & 130 & 28.1 & & \\
\hline Tumor size, mm & 462 & - & 20 & $1-110$ \\
\hline \multicolumn{5}{|l|}{ pT stage } \\
\hline I & 247 & 53.5 & & \\
\hline II-IV & 215 & 46.5 & & \\
\hline \multicolumn{5}{|l|}{$\mathrm{pN}$ stage } \\
\hline 0 & 240 & 51.9 & & \\
\hline I-III & 222 & 48.1 & & \\
\hline \multicolumn{5}{|l|}{ pStage } \\
\hline I & 166 & 35.9 & & \\
\hline II & 198 & 42.9 & & \\
\hline III & 98 & 21.2 & & \\
\hline \multicolumn{5}{|l|}{ ER } \\
\hline Positive & 376 & 81.4 & & \\
\hline Negative & 86 & 18.6 & & \\
\hline \multicolumn{5}{|l|}{ PR } \\
\hline Positive & 309 & 66.9 & & \\
\hline Negative & 153 & 33.1 & & \\
\hline \multicolumn{5}{|l|}{ HER-2 expression } \\
\hline Positive & 99 & 21.4 & & \\
\hline Negative & 363 & 78.6 & & \\
\hline Ki-67 expression, \% & 462 & - & 20 & $1-95$ \\
\hline$<15$ & 181 & 39.2 & & \\
\hline$\geq 15$ & 281 & 60.8 & & \\
\hline
\end{tabular}

ER, estrogen receptor; PR, progesterone receptor; HER-2, human epidermal growth factor receptor-2; IDC, invasive ductal carcinoma; pT, pathological tumor; pN, pathological nodal. negativity $(\mathrm{P}<0.001)$ and HER-2 overexpression $(\mathrm{P}<0.001)$ were identified as demographical and pathological parameters associated with Ki-67 expression. The qualitative comparisons revealed a negative correlation between $\mathrm{Ki}-67$ expression and the hormone receptor positivity ratio $(\mathrm{r}=-0.489 ; \mathrm{P}<0.001)$, and a positive correlation between $\mathrm{Ki}-67$ expression and tumor size $(r=0.259 ; \mathrm{P}<0.001)$ (Table III; Figs. 1 and 2).

Multivariate analysis (logistic regression analysis). The multiple logistic regression analysis revealed that a Ki-67 cut-off value of $\geq 15 \%$ was associated with the largest number of prognostic factors ( $\leq 40$ years old, IDC histology, high HG III, ER negativity and HER-2 positivity) among the four selected cut-off values ( $\geq 10, \geq 15, \geq 20$ and $\geq 25 \%$ ) (Table IV).

$D F S$. The median follow-up time was 25 months (range, 17-41 months). In total, locoregional and systemic tumor recurrence was observed in two and five patients, respectively. The Kaplan-Meier analysis revealed that the three-year DFS and OS rates were 97 and 100\%, respectively. The univariate analysis revealed that ER negativity, a high HG (III), LVI and high Ki-67 expression ( $\geq 15 \%$ ) were negatively associated with the DFS rate (Table V). Among the four Ki-67 cut-off groups in the luminal A and B1 molecular subtypes, a Ki-67 level of $\geq 15 \%$ was identified as the only statistically significant value. The DFS rate was higher in patients with the luminal A subtype compared with the luminal B1 subtype (100 vs. 93.6\%; $\mathrm{P}=0.036$; Table VI).

\section{Discussion}

During the last decade, the overall incidence of $\mathrm{BC}$ has declined in the United States and other developed countries (26,27). However, the incidence of biologically aggressive BCs, such as the HR-negative, triple-negative and high-proliferative index subtypes has increased in low- to middle-income countries, and also in African-American populations in developed countries $(19,27,28)$. Recent studies have identified a significant increase in HR-negative and high-grade BC subtypes within these populations (19,29-32). The HR-negative subtype, of which $50 \%$ of cases are also HER-2-negative, is a biologically aggressive form of BC, which is resistant to conventional cytotoxic chemotherapy, and is associated with a reduced survival rate compared with other known subtypes (33-36). These negative outcomes, and the high tumor proliferation rates observed, may be associated with a young age at the time of diagnosis, ethnicity and the different biological characteristics of tumor subtypes.

To the best of our knowledge, the present study is the first to assess the tumor proliferation status in a large cohort of Turkish females with BC. The retrospective analysis not only presented the Ki-67 cut-off value, but also investigated the association between the clinicopathological prognostic factors and the Ki-67 cut-off level. In total, $24.5 \%$ of the patients were $<40$ years old, and the median and optimal cut-off values of the Ki-67 level were 20 and $15 \%$, respectively. Furthermore, $61 \%$ of patients exhibited a Ki-67 value of $\geq 15 \%$, a level which represented a high-risk population.

The present study aimed to identify prognostic factors that were associated with Ki-67 expression. A younger 
Table III. Prognostic factors associated with Ki-67 expression $(\mathrm{n}=462)$.

\begin{tabular}{|c|c|c|c|c|c|c|}
\hline \multirow[b]{2}{*}{ Prognostic factor } & \multicolumn{5}{|c|}{ Ki-67 expression, $\%$} & \multirow[b]{2}{*}{ P-value } \\
\hline & $\begin{array}{l}<10 \\
\mathrm{n}(\%)\end{array}$ & $\begin{array}{l}10-14, \\
\text { n }(\%)\end{array}$ & $\begin{array}{c}15-<20 \\
\mathrm{n}(\%)\end{array}$ & $\begin{array}{l}20-24 \\
\mathrm{n}(\%)\end{array}$ & $\begin{array}{l}\geq 25, \\
\mathrm{n}(\%)\end{array}$ & \\
\hline Age, years & & & & & & $<0.001$ \\
\hline$>40$ & $86(84.3)$ & $69(87.3)$ & $29(76.3)$ & $35(83.3)$ & $130(64.7)$ & \\
\hline$\leq 40$ & $16(15.7)$ & $10(12.7)$ & $9(23.7)$ & $7(16.7)$ & $71(35.3)$ & a-bcde*; ab-cde ${ }^{* * *}$ \\
\hline Tumor type & & & & & & 0.001 \\
\hline IDC & $69(67.6)$ & $58(73.4)$ & $33(86.8)$ & $34(81.0)$ & $174(86.6)$ & \\
\hline Other & $33(32.4)$ & $21(26.6)$ & $5(13.2)$ & $8(19.0)$ & $27(13.4)$ & ab-cd ${ }^{*} ; a-b c d e^{* *} ; a b-c d e^{* * *}$ \\
\hline pT stage & & & & & & $<0.001$ \\
\hline I & $76(74.5)$ & $41(51.9)$ & $23(60.5)$ & $20(47.6)$ & $87(43.3)$ & $a-b^{* *}$ \\
\hline II-III & $26(25.5)$ & $38(48.1)$ & $15(39.5)$ & $22(52.4)$ & $114(56.7)$ & a-bcde ${ }^{* * *} ;$ ab-cde $e^{* * *}$ \\
\hline $\mathrm{pN}$ stage & & & & & & 0.091 \\
\hline 0 & $64(62.7)$ & $43(54.4)$ & $16(42.1)$ & $19(45.2)$ & $98(48.8)$ & \\
\hline I-III & $38(37.3)$ & $36(45.6)$ & $22(57.9)$ & $23(54.8)$ & $103(51.2)$ & ab-cd*; a-bcde* $; a b-c d e^{*}$ \\
\hline pStage & & & & & & 0.004 \\
\hline I & $55(53.9)$ & $30(38.0)$ & $13(34.2)$ & $12(28.6)$ & $56(27.9)$ & $a-b^{*}$ \\
\hline II & $35(34.3)$ & $30(38.0)$ & $17(44.7)$ & $20(47.6)$ & $96(47.8)$ & a-bcde ${ }^{* * *} ;$ ab-cde ${ }^{* * *}$ \\
\hline III & $12(11.8)$ & $19(24.1)$ & $8(21.1)$ & $10(23.8)$ & $49(24.4)$ & \\
\hline Focality & & & & & & 0.951 \\
\hline Unifocal & $84(82.4)$ & $65(82.3)$ & $33(86.8)$ & $36(85.7)$ & $166(82.6)$ & \\
\hline Multifocal/multicentric & $18(17.6)$ & $14(17.7)$ & $5(13.2)$ & $6(14.3)$ & $35(17.4)$ & \\
\hline $\mathrm{HG}$ & & & & & & $<0.001$ \\
\hline I-II & $87(85.3)$ & $56(70.9)$ & $21(55.3)$ & $19(45.2)$ & $33(16.4)$ & $a-b^{*} ; a b-c d^{* * *}$ \\
\hline III & $15(14.7)$ & $23(29.1)$ & $17(44.7)$ & $23(54.8)$ & $168(83.6)$ & a-bcde $* * * ; a b-c d e * * *$ \\
\hline NG & & & & & & $<0.001$ \\
\hline I-II & $70(68.6)$ & $44(55.7)$ & 12 (31.6) & $17(40.5)$ & $30(14.9)$ & b-c $; a b-c d^{* * *}$ \\
\hline III & $32(31.4)$ & $35(44.3)$ & $26(68.4)$ & $25(59.5)$ & $171(85.1)$ & a-bcde ${ }^{* * *} ; a b-c d e e^{* * *}$ \\
\hline LVI & & & & & & 0.001 \\
\hline Present & $30(29.4)$ & $31(39.2)$ & $23(60.5)$ & $21(50.0)$ & $104(51.7)$ & b-c $c^{*} ; a b-c d^{* *}$ \\
\hline Absent & $72(70.6)$ & $48(60.8)$ & $15(39.5)$ & $21(50.0)$ & $97(48.3)$ & a-bcde $e^{* * *} ;$ ab-cde $e^{* * *}$ \\
\hline EIC & & & & & & 0.530 \\
\hline Present & $67(65.7)$ & $59(74.7)$ & $27(71.1)$ & $29(69.0)$ & $150(74.6)$ & \\
\hline Absent & $35(34.3)$ & $20(25.3)$ & $11(28.9)$ & $13(31.0)$ & $51(25.4)$ & \\
\hline ER & & & & & & $<0.001$ \\
\hline Positive & $99(97.1)$ & $76(96.2)$ & $36(94.7)$ & $39(92.9)$ & $126(62.7)$ & \\
\hline Negative & $3(2.9)$ & $3(3.8)$ & $2(5.3)$ & $3(7.1)$ & $75(37.3)$ & a-bcde ${ }^{* * *} ; a b-c d e^{* * *}$ \\
\hline $\mathrm{PR}$ & & & & & & $<0.001$ \\
\hline Positive & $84(82.4)$ & $65(82.3)$ & $31(81.6)$ & $32(76.2)$ & $97(48.3)$ & \\
\hline Negative & $18(17.6)$ & $14(17.7)$ & $7(18.4)$ & $10(23.8)$ & $104(51.7)$ & a-bcde ${ }^{* * *} ; a b-c d e^{* * *}$ \\
\hline HER-2 & & & & & & $<0.001$ \\
\hline Negative & $102(100.0)$ & $69(87.3)$ & $29(76.3)$ & $28(66.7)$ & $135(67.2)$ & $a-b^{* * *} ; a b-c d^{* * * *}$ \\
\hline Positive & $0(0.0)$ & $10(12.7)$ & $9(23.7)$ & $14(33.3)$ & $66(32.8)$ & a-bcde ${ }^{* * *} ; a b-c d e^{* * *}$ \\
\hline
\end{tabular}

pT, pathological tumor; pN, pathological nodal; HG, histological grade; NG, nuclear grade; LVI, lymphovascular invasion; EIC, extensive intraductal component; ER, estrogen receptor; PR, progesterone receptor; HER-2, human epidermal growth factor receptor-2. Letters are representative of each column: a, $<10 \%$; b, 10-14\%; c, 15-20\%; d, 20-24\%; and e, $\geq 25 \%$. ${ }^{*} \mathrm{P}<0.05 ;{ }^{* * *} \mathrm{P}<0.01$; and ${ }^{* * *} \mathrm{P}<0.001$. (Pearson $\chi^{2}$, continuity correction and Fisher's exact tests). 
Table IV. Independent prognostic factors associated with Ki-67 expression $(n=462)$.

\begin{tabular}{|c|c|c|c|c|c|c|}
\hline \multicolumn{7}{|l|}{$\mathrm{A}, \geq 10 \% \mathrm{Ki}-67$} \\
\hline Factors & $\mathrm{B}$ & S.E. & Wald & df & P-value & $\operatorname{Exp}(B)$ \\
\hline IDC histology & 0.747 & 0.290 & 6.612 & 1 & 0.010 & 2.110 \\
\hline Large tumor size (20 mm) & 1.020 & 0.276 & 13.615 & 1 & 0.000 & 2.772 \\
\hline HG III & 2.154 & 0.306 & 49.675 & 1 & 0.000 & 8.623 \\
\hline Constant value & 1.472 & 0.172 & 73.421 & 1 & 0.000 & 4.356 \\
\hline
\end{tabular}

B, $\geq 15 \%$ Ki-67

\begin{tabular}{lcccrr}
\hline Factors & B & S.E. & Wald & df & P-value \\
\hline Age ( $\leq 40$ years) & 0.718 & 0.290 & 6.105 & 1 & 0.013 \\
Histologic type (IDC) & 0.657 & 0.287 & 5.241 & 1 & 0.022 \\
ER negativity & 1.423 & 0.473 & 9.068 & 1 & 0.003 \\
HG III & 1.822 & 0.247 & 54.588 & 1 & 0.000 \\
HER-2 positivity & 1.323 & 0.384 & 11.878 & 1 & 0.001 \\
Constant value & 1.506 & 0.291 & 26.705 & 1 & 0.000 \\
\hline
\end{tabular}

C, $\geq 20 \%$ Ki-67

\begin{tabular}{|c|c|c|c|c|c|c|}
\hline Factors & B & S.E. & Wald & df & P-value & $\operatorname{Exp}(B)$ \\
\hline Age ( $\leq 40$ years $)$ & 0.717 & 0.274 & 6.864 & 1 & 0.009 & 2.049 \\
\hline ER negativity & 1.606 & 0.412 & 15.189 & 1 & 0.000 & 4.980 \\
\hline HG III & 1.885 & 0.237 & 63.370 & 1 & 0.000 & 6.587 \\
\hline HER-2 positivity & 0.923 & 0.315 & 8.592 & 1 & 0.003 & 2.516 \\
\hline Constant value & 1.119 & 0.237 & 22.317 & 1 & 0.000 & 3.061 \\
\hline
\end{tabular}

D, $\geq 25 \%$ Ki-67

\begin{tabular}{lcccrrr}
\hline Factors & B & S.E. & Wald & df & P-value \\
\hline Age ( $\leq 40$ years) & 1.007 & 0.271 & 13.761 & 1 & 0.000 & 2.736 \\
ER negativity & 1.928 & 0.368 & 27.424 & 1 & 0.000 & 6.877 \\
HG III & 2.060 & 0.247 & 69.408 & 1 & 0.000 & 7.847 \\
Constant value & 0.469 & 0.204 & 5.278 & 1 & 0.022 \\
\hline
\end{tabular}

Multivariate logistic regression model. IDC, invasive ductal carcinoma; HG, histological grade; ER, estrogen receptor; HER-2, human epidermal growth factor receptor-2; S.E., standard error; df, degrees of freedom.

age ( $\leq 40$ years old), an IDC tumor type, HG/NG III, LVI, HR-negativity, HER-2 positivity and pT stage (tumor size) were revealed as poor prognostic factors associated with high expression levels of Ki-67. By contrast, the Ki-67 index was negatively correlated with HR positivity, and positively correlated with an increasing tumor size $(\mathrm{P}<0.001)$.

The majority of previous studies have identified the same poor prognostic factors associated with high levels of Ki-67. In particular, a higher tumor grade was revealed to be the most significant poor prognostic parameter $(12,37-40,42)$. In a previous study, the reference cut-off value for Ki-67 expression was set at $15 \%$, similar to the current literature $(1,8,13)$, and the study identified a significant correlation between the tumor grading and the Ki-67 level (37). In the present study, the HG was revealed as an independent prognostic factor for each cut-off value group, and was correlated with a high level of Ki-67 expression. Previous studies demonstrated that the ER status was inversely associated with the Ki-67 index, and that low-proliferating tumors exhibited higher ER positivity rates (12,28,37-41), but that HER-2 expression rates were positively correlated with higher Ki-67 levels $(28,37,38)$. In regard to tumor size, certain studies $(12,30,38,42,43)$, including the present study, have identified a positive association with the Ki-67 index, however, others have not $(37,40,41)$. A higher nodal status, which has been recognized as a significant prognostic factor for $\mathrm{BC}$, has been associated with a higher Ki-67 index in previous studies $(37,38,43)$, but not in the current study. 
Table V. Factors associated with DFS.

\begin{tabular}{|c|c|c|c|}
\hline Factors & DFS, $\%$ & $\chi^{2}$ & P-value \\
\hline All cohorts & 97.0 & & \\
\hline ER & & 6.935 & $0.008^{\mathrm{a}}$ \\
\hline Positive & 98.0 & & \\
\hline Negative & 93.0 & & \\
\hline Histological grade & & 6.745 & $0.009^{\mathrm{a}}$ \\
\hline I-II & 100.0 & & \\
\hline III & 94.1 & & \\
\hline LVI & & 3.998 & $0.046^{\mathrm{a}}$ \\
\hline Negative & 99.4 & & \\
\hline Positive & 94.6 & & \\
\hline \multicolumn{4}{|l|}{$\mathrm{Ki}-67, \%$} \\
\hline$<10$ & 100.0 & 2.461 & 0.117 \\
\hline$\geq 10$ & 96.0 & & \\
\hline $\mathrm{Ki}-67, \%$ & & 5.525 & $0.019^{\mathrm{b}}$ \\
\hline$<15$ & 100.0 & & \\
\hline$\geq 15$ & 94.6 & & \\
\hline $\mathrm{Ki}-67, \%$ & & 1.683 & 0.194 \\
\hline$<20$ & 98.2 & & \\
\hline$\geq 20$ & 95.7 & & \\
\hline $\mathrm{Ki}-67, \%$ & & 3.297 & 0.069 \\
\hline$<25$ & 98.4 & & \\
\hline$\geq 25$ & 94.8 & & \\
\hline
\end{tabular}

DFS, disease-free survival; ER, estrogen receptor; LVI, lymphovascular invasion. ${ }^{\mathrm{a}} \mathrm{P}<0.01 ;{ }^{\mathrm{b}} \mathrm{P}<0.05 \cdot \chi^{2}$ was calculated by log-rank test.

Table VI. DFS according to the different molecular subtypes $(n=462)$.

\begin{tabular}{lcrcr}
\hline $\begin{array}{l}\text { Molecular } \\
\text { classification }\end{array}$ & $\begin{array}{c}\text { Ki-67, } \\
\%\end{array}$ & $\begin{array}{c}\text { DFS, } \\
\%\end{array}$ & $\chi^{2}$ & P-value \\
\hline $\begin{array}{l}\text { Luminal-A } \\
\text { Luminal-B1 [HER-2(-)] }\end{array}$ & $\geq 10$ & 100.0 & 1.980 & 0.159 \\
Luminal-A & $<15$ & 100.0 & 4.386 & $0.036^{\mathrm{a}}$ \\
Luminal-B1 [HER-2(-)] & $\geq 15$ & 93.6 & & \\
Luminal-A & $<20$ & 97.8 & 0.013 & 0.909 \\
Luminal-B1 [HER-2(-)] & $\geq 20$ & 96.3 & & \\
Luminal-A & $<25$ & 98.0 & 0.152 & 0.697 \\
Luminal-B1 [HER-2(-)] & $\geq 25$ & 95.5 & & \\
Luminal-B2 [HER-2(+)] & - & 100.0 & 3.675 & 0.159 \\
Triple(-) & - & 91.2 & & \\
HER-2-enriched & - & 93.2 & & \\
\end{tabular}

DFS, disease-free survival; HER-2, human epidermal growth factor-2. ${ }^{\mathrm{a}} \mathrm{P}<0.05 \cdot \chi^{2}$ was calculated by $\log$-rank test.

In recent decades, $\mathrm{Ki}-67$ has been investigated as a potential immunohistochemical marker of proliferating cells, and an increasing amount of evidence now exists to support the use of Ki-67 as a clinical indicator of early BC (13). Despite the published studies that have analyzed the prognostic role of $\mathrm{Ki}-67$ in BC, uncertainty remains concerning the assessment of $\mathrm{Ki}-67$, partly due to the fact that the majority of the studies were retrospective $(12,15)$. As no clear evidence exists regarding the methodology of how to interpret and score Ki-67 levels, or a definition of set Ki-67 cut-off values, the routine use of Ki-67 is not advocated. In 2011, Dowsett et al (21) published a set of recommendations for the worldwide standardization assessment of $\mathrm{Ki}-67$ in BC. However, the methods used to evaluate the Ki-67 levels were highly variable across the laboratories, and were difficult to compare with the results of published studies (45). In the literature, the cut-off values were chosen or defined by investigators, and the threshold definitions of Ki-67 were accepted as mean or median values, or as an established arbitrary value (13). Cheang et al (45) identified that the ideal $\mathrm{Ki}-67$ index cut-off value, to distinguish luminal $\mathrm{A}$ and $\mathrm{B}$ molecular subtypes, was $14 \%$. This value was then recommended for clinical use in the 2011 St. Gallen International Expert Consensus on the Primary Therapy of Early Breast Cancer (1). The study by Cheang et al (45) presented two issues: i) Tissue microarrays, which were unable to reveal tumor heterogeneity as objectively as whole tissue sections, were used; and ii) the methodology used for Ki-67 counting was not clearly described. In two different meta-analyses, the cut-off values for the Ki-67 index varied from 0-34\% $(8,15)$. Despite the accepted 2011 St. Gallen Ki-67 cut-off value of $14 \%$ to differentiate between the luminal subtypes (1), the $2013 \mathrm{St}$. Gallen consensus identified a novel cut-off value of $20 \%$ (17). Randomized prospective studies may be designed to confirm the optimum Ki-67 cut-off value of $20 \%$.

A recent study by Aleskandarany et al (43) evaluated the prognostic significance of $\mathrm{Ki}-67$ within $\mathrm{BC}$ molecular subtypes. The study concluded that the Ki-67 index was able to distinguish between the luminal subgroups of patients with $\mathrm{BC}$ and different clinical outcomes. However, due to high proliferative activity, the Ki-67 index exhibited limited ability in stratifying HER-2-enriched and TNBC subtypes. In the present study, the median Ki-67 levels were 10, 30, 40 and 75\% in luminal A and B, HER-2-positive and TNBC molecular subtypes, respectively (Table I). In accordance with previous studies $(28,37,38,42)$, the levels of Ki-67 were significantly higher in patients with HER-2-positive and TNBC subtypes.

To determine the ideal Ki-67 cut-off value, and reveal any associations with poor prognostic factors and DFS/OS rates, the $\mathrm{Ki}-67$ values were categorized into five groups $(<10,10-14,15-19,20-24$ and $\geq 25 \%)$. In total, five independent poor prognostic factors (age of $\leq 40$ years, IDC histological subtype, ER negativity, HG III and HER-2 positivity; Table IV) were identified to be associated with $\mathrm{Ki}-67$ values of $\geq 15 \%$. A $\mathrm{Ki}-67$ index of $>25 \%$ generally reflects an aggressive type of $\mathrm{BC}$, and a systemic treatment decision is not challenging in highly proliferative tumors. In the present study, a patient age of $\leq 40$ years, ER negativity and HG III were revealed to be associated with Ki-67 values of $\geq 25 \%$.

TNBC is a heterogeneous disease, and exhibits different prognostic subgroups. High Ki-67 levels are often observed in cases of TNBC. Munzone et al (42) analyzed 496 node-negative TNBC patients, with a mean age of 52 years and a median 
Ki-67 level of $48 \%$ (range, 4-95\%). The study revealed that the Ki-67 index increased with decreasing age and increasing tumor size and grade. Furthermore, the Ki-67 level was significantly higher in the ductal TNBC cases, compared with the other histological types. Nishimura et al (38) analyzed $2,638 \mathrm{BC}$ patients, with a mean age, tumor diameter and $\mathrm{Ki}-67$ value of 52.2 years, $2.2 \mathrm{~cm}$ and $20 \%$, respectively. The majority of the cases were IDC, with a median Ki-67 index of $22 \%$. The characteristics between this Japanese population and the Turkish females in the present study were quite similar. If the Japanese and Turkish BC patients were compared according to molecular subtypes (luminal A and B, HER-2-enriched and TNBC) the median Ki-67 values were identified as 17, 29, 40 and $50 \%$ in the Japanese series, and 10, 30, 40 and $75 \%$ in the present study, respectively. A higher Ki-67 index (>20\%) was significantly correlated with a higher tumor grade and lower DFS and OS rates in the Japanese study.

The limitation of the present study was the short follow-up time (median, 25 months), and the small number of tumor recurrences (two loco-regional and five systemic) that were observed within this period of time. Therefore, the study mainly focused on the association between the prognostic parameters and the Ki-67 index, rather than the prognostic effect of the Ki-67 index on DFS and OS. The association between the poor prognostic factors and the high Ki-67 index was revealed in the study. The Kaplan-Meier estimates for the three-year DFS and OS rates were 97 and 100\%, respectively. A $\mathrm{Ki}-67$ value of $\geq 15 \%$ was revealed to be significant in its ability to distinguish between the HER-2-negative luminal A and B1 tumor subtypes, with a higher DFS rate in patients with the luminal A subtype compared with the luminal B1 subtype $(\mathrm{P}=0.036)$.

According to the St. Gallen 2013 consensus (17), a distinction between HER-2-negative luminal A and luminal B1 tumors can be made by ER, PR and Ki-67 expression levels, and can be determined only by laboratories with quality assurance programs. The strength of the present study was that all the pathological analyses were performed by a single, experienced breast pathologist in one laboratory. Previous, extended follow-up studies have included patients who had not received chemotherapy, or patients who had received a cyclophosphamide, methotrexate and fluorouracil regimen $(40,42)$. The present, single-center study identified that for BC patients, a Ki-67 cut-off value of $15 \%$ was valuable for the distinction between molecular subtypes. This cut-off value was detected in patients treated with current systemic and irradiation modalities, and who were monitored for up to 41 months.

In conclusion, the optimal $\mathrm{Ki}-67$ cut-off value for $\mathrm{BC}$ patients was identified as $15 \%$ for the distinction between different luminal subtypes. The high Ki-67 proliferation index was revealed to be significantly correlated with a young age, high tumor grade, IDC type, ER negativity and HER-2 positivity. An extended follow-up time is required in order to demonstrate the efficacy of the current treatment modalities for patients with different molecular subtypes and different Ki-67 cut-off values. The significance of the Ki-67 index has been investigated over the last decade, and may become a standard prognostic factor for future clinical use.

\section{References}

1. Goldhirsch A, Wood WC, Coates AS, et al; Panel members: Strategies for subtypes - dealing with the diversity of breast cancer: highlights of the St. Gallen International Expert Consensus on the Primary Therapy of Early Breast Cancer 2011. Ann Oncol 22: 1736-1747, 2011.

2. Hanahan D and Weinberg RA: The hallmarks of cancer. Cell 100: $57-70,2000$

3. Milde-Langosch K, Karn T, Müller V, et al: Validity of the proliferation markers Ki67, TOP2A, and RacGAP1 in molecular subgroups of breast cancer. Breast Cancer Res Treat 137: 57-67, 2013.

4. Wirapati P, Sotiriou C, Kunkel S, et al: Meta-analysis of gene expression profiles in breast cancer: toward a unified understanding of breast cancer subtyping and prognosis signatures. Breast Cancer Res 10: R65, 2008.

5. Bilir A, Ozmen V, Kecer M, et al: Thymidine labeling index: prognostic role in breast cancer. Am J Clin Oncol 27: 400-406, 2004.

6. Garcia RL, Coltrera MD and Gown AM: Analysis of proliferative grade using anti-PCNA/cyclin monoclonal antibodies in fixed, embedded tissues. Comparison with flow cytometric analysis. Am J Pathol 134: 733-739, 1989.

7. Ignatiadis $M$ and Sotiriou C: Understanding the molecular basis of histologic grade. Pathobiology 75: 104-111, 2008.

8. Stuart-Harris R, Caldas C, Pinder SE and Pharoah P: Proliferation markers and survival in early breast cancer: a systematic review and meta-analysis of 85 studies in 32,825 patients. Breast 17: 323-334, 2008

9. Gerdes J, Schwab U, Lemke H and Stein H: Production of a mouse monoclonal antibody reactive with a human nuclear antigen associated with cell proliferation. Int J Cancer 31: 13-20, 1983.

10. Gerdes J, Lemke H, Baisch H, et al: Cell cycle analysis of a cell proliferation-associated human nuclear antigen defined by the monoclonal antibody Ki-67. J Immunol 133: 1710-1715, 1984.

11. Scholzen T and Gerdes J: The Ki-67 protein: from the known and the unknown. J Cell Physiol 182: 311-322, 2000.

12. Urruticoechea A, Smith IE and Dowsett M: Proliferation marker Ki-67 in early breast cancer. J Clin Oncol 23: 7212-7220, 2005.

13. Yerushalmi R, Woods R, Ravdin PM, Hayes MM and Gelmon KA: Ki67 in breast cancer: prognostic and predictive potential. Lancet Oncol 11: 174-183, 2010.

14. Luporsi E, André F, Spyratos F, et al: Ki-67: level of evidence and methodological considerations for its role in the clinical management of breast cancer: analytical and critical review. Breast Cancer Res Treat 132: 895-915, 2012.

15. de Azambuja E, Cardoso F, de Castro G Jr, et al: Ki-67 as prognostic marker in early breast cancer: a meta-analysis of published studies involving 12,155 patients. Br J Cancer 96: 1504-1513, 2007.

16. Lester SC, Bose S, Chen YY, Connolly JL, de Baca ME, Fitzgibbons PL, Hayes DF, Kleer C, O'Malley FP, Page DL, et al; Members of the Cancer Committee, College of American Pathologists: Protocol for the examination of specimens from patients with invasive carcinoma of the breast. Arch Pathol Lab Med 133: 1515-1538, 2009.

17. Goldhirsch A, Winer EP, Coates AS, et al; Panel members: Personalizing the treatment of women with early breast cancer: highlights of the St. Gallen International Expert Consensus on the Primary Therapy of Early Breast Cancer 2013. Ann Oncol 24: 2206-2223, 2013.

18. Perou CM, Sørlie T, Eisen MB, et al: Molecular portraits of human breast tumours. Nature 406: 747-752, 2000.

19. Ozmen V: Breast Cancer in the World and Turkey. J Breast Health 4: 7-12, 2008.

20. McShane LM, Altman DG, Sauerbrei W, et al; Statistics Subcommittee of NCI-EORTC Working Group on Cancer Diagnostics: REporting recommendations for tumor MARKer prognostic studies (REMARK). Breast Cancer Res Treat 100: 229-235, 2006

21. Dowsett M, Nielsen TO, A'Hern R, et al; International Ki-67 in Breast Cancer Working Group: Assessment of Ki67 in breast cancer: recommendations from the International Ki67 in Breast Cancer Working Group. J Natl Cancer Inst 103: 1656-1664, 2011.

22. Hammond ME, Hayes DF, Dowsett M, et al: American Society of Clinical Oncology/College of American Pathologists guideline recommendations for immunohistochemical testing of estrogen and progesterone receptors in breast cancer (unabridged version). Arch Pathol Lab Med 134: e48-e72, 2010. 
23. Wolff AC, Hammond ME, Schwartz JN, et al; American Society of Clinical Oncology; College of American Pathologists: American Society of Clinical Oncology/College of American Pathologists guideline recommendations for human epidermal growth factor receptor 2 testing in breast cancer. Arch Pathol Lab Med 131: 18-43, 2007.

24. Elston CW and Ellis IO: Pathological prognostic factors in breas cancer.I. The value of histological grade in breast cancer: experience from a large study with long-term follow-up. Histopathology 19 : 403-410, 1991.

25. Fisher ER, Redmond $\mathrm{C}$ and Fisher B: Histologic grading of breast cancer. Pathol Annu 15: 239-251, 1980.

26. Couris CM, Polazzi S, Olive F, et al: Breast cancer incidence using administrative data: correction with sensitivity and specificity. J Clin Epidemiol 62: 660-666, 2009.

27. Jemal A, Bray F, Center MM, et al: Global cancer statistics. CA Cancer J Clin 61: 69-90, 2011.

28. Hafeez F, Neboori HJ, Harigopal M, et al: Is Ki-67 expression prognostic for local relapse in early-stage breast cancer patients treated with breast conservation therapy (BCT)? Int J Radiat Biol Phys 87: 344-348, 2013

29. Lin CH, Liau JY, Lu YS, et al: Molecular subtypes of breast cancer emerging in young women in Taiwan: evidence for more than just westernization as a reason for the disease in Asia. Cancer Epidemiol Biomarkers Prev 18: 1807-1814, 2009.

30. Adebamowo CA, Famooto A, Ogundiran TO, et al: Immunohistochemical and molecular subtypes of breast cancer in Nigeria. Breast Cancer Res Treat 110: 183-188, 2008.

31. Ihemelandu CU, Leffall LD Jr, Dewitty RL, et al: Molecular breas cancer subtypes in premenopausal and postmenopausal AfricanAmerican women: age-specific prevalence and survival. J Surg Res 143: 109-118, 2007.

32. Nichols HB, Trentham-Dietz A, Love RR, et al: Differences in breast cancer risk factors by tumor marker subtypes among premenopausal Vietnamese and Chinese women. Cancer Epidemiol Biomarkers Prev 14: 41-47, 2005.

33. Akiyama F and Iwase H: Triple negative breast cancer: clinicopathological characteristics and treatment strategies. Breast Cancer 16 252-253, 2009

34. Alli E, Sharma VB, Sunderesakumar P and Ford JM: Defective repair of oxidative dna damage in triple-negative breast cancer confers sensitivity to inhibition of poly (ADP-ribose) polymerase. Cancer Res 69: 3589-3596, 2009.
35. Bouchalova K, Cizkova M, Cwiertka K, Trojanec R and Hajduch M: Triple negative breast cancer - current status and prospective targeted treatment based on HER1 (EGFR), TOP2A and C-MYC gene assessment. Biomed Pap Med Fac Univ Palacky Olomouc Czech Repub 153: 13-17, 2009.

36. Carey LA, Dees EC, Sawyer L, et al: The triple negative paradox: primary tumor chemosensitivity of breast cancer subtypes. Clin Cancer Res 13: 2329-2334, 2007.

37. Inwald EC, Klinkhammer-Schalke M, Hofstädter F, et al: $\mathrm{Ki}-67$ is a prognostic parameter in breast cancer patients: results of a large population-based cohort of a cancer registry. Breast Cancer Res Treat 139: 539-552, 2013.

38. Nishimura R, Osako T, Okumura Y, et al: Ki-67 as a prognostic marker according to breast cancer subtype and a predictor of recurrence time in primary breast cancer. Exp Ther Med 1: 747-754, 2010

39. DeCensi A, Guerrieri-Gonzaga A, Gandini S, et al,: Prognostic significance of Ki-67 labeling index after shortterm presurgical tamoxifen in women with ER-positive breast cancer. Ann Oncol 22: 582-587, 2011.

40. Aleskandarany MA, Green AR, Rakha EA, et al: Growth fraction as a predictor of response to chemotherapy in nodenegative breast cancer. Int J Cancer 126: 1761-1769, 2010.

41. Tanei T, Shimomura A, Shimazu K, et al: Prognostic significance of $\mathrm{Ki}-67$ index after neoadjuvant chemotherapy in breast cancer. Eur J Surg Oncol 37: 155-161, 2011.

42. Munzone E, Botteri E, Sciandivasci A, et al: Prognostic value of Ki-67 labeling index in patients with node-negative, triple-negative breast cancer. Breast Cancer Res Treat 134: 277-282, 2012.

43. Aleskandarany MA, Green AR, Benhasouna AA, et al: Prognostic value of proliferation assay in the luminal, HER2-positive, and triple-negative biologic classes of breast cancer. Breast Cancer Res 14: R3, 2012.

44. Pathmanathan N and Balleine RL: Ki67 and proliferation in breast cancer. J Clin Pathol 66: 512-516, 2013.

45. Cheang MC, Chia SK, Voduc D, et al: Ki67 index, HER2 status, and prognosis of patients with luminal B breast cancer. J Natl Cancer Inst 101: 736-750, 2009. 